\title{
Auditory feedback and memory for music performance: Sound evidence for an encoding effect
}

\author{
STEVEN A. FINNEY and CAROLINE PALMER \\ Ohio State University, Columbus, Ohio
}

\begin{abstract}
Research on the effects of context and task on learning and memory has included approaches that emphasize processes during learning (e.g., Craik \& Tulving, 1975) and approaches that emphasize a match of conditions during learning with conditions during a later test of memory (e.g., Morris, Bransford, \& Franks, 1977; Proteau, 1992; Tulving \& Thomson, 1973). We investigated the effects of auditory context on learning and retrievalin three experiments on memorized music performance (a form of serial recall). Auditory feedback (presence or absence) was manipulated while pianists learned musical pieces from notation and when they later played the pieces from memory. Auditory feedback during learning significantly improved later recall. However, auditory feedback at test did not significantly affect recall, nor was there an interaction between conditions at learning and test. Auditory feedback in music performance appears to be a contextual factor that affects learning but is relatively independent of retrieval conditions.
\end{abstract}

Researchers in learning and memory have frequently reported effects of task and context on retention. Verbal materials are remembered better if they are initially generated by the subject than if they are merely perceived by the subject (Slamecka \& Graf, 1978), and actively generated movements have been found to be remembered more accurately than passive movements (Hall \& Leavitt, 1977; Marteniuk, 1973; Roy, 1978). Memory for verbal material presented in the auditory modality during learning has been reported to be superior to that for material presented visually (Mowbray \& Gebhard, 1958; Murray et al., 1999; Penney, 1989). Craik and Lockhart (1972) and Craik and Tulving (1975) demonstrated that memory for visually presented words was superior when the orienting task during learning was to answer a semantic question (e.g., "Does the word refer to an ani-

This work was supported by NIMH Grant R01-MH45764 to C.P., and by an Ohio State University postdoctoral fellowship in music cognition to S.A.F. Portions of this work were presented at the 41 st Annual Meeting of the Psychonomic Society. We thank Rich Jagacinski and Neal Johnson for helpful discussion; Zeb Highben, Anna-Lisa Ventola, and Grant Baldwin for assistance in preparing and running experiments; Peter Eimas, Bruce Kay, Luc Proteau, Bruno Repp, and an anonymous reviewer for helpful comments on earlier versions of this article; Thanassi Protopapas for ongoing assistance with the LaTeX APA macro set (http://www.ctan.org/tex-archive/macros/latex/contrib/other/apa), and P. Douglas Reeder, Shane Ruland, and Larry Campbell for hardware and software assistance. S.A.F. also thanks Jim Anderson and Peter Eimas for their enthusiasm for classics such as James (1890) and Lashley (1951). Correspondence may be addressed to S. A. Finney (e-mail preferred), P. O. Box 133, Honolulu, HI 96810 (e-mail: sf@sfinney.org), or C. Palmer, Department of Psychology, Ohio State University, 1885 Neil Avenue, Columbus, OH, 43210 (e-mail: palmer.1@ osu.edu). mal?") than when the task was a question relating to orthography or rhyme.

Such studies emphasized conditions during learning and paid little attention to retrieval processes. However, subsequent work in both verbal and motor learning has focused on the interaction of conditions at learning with conditions at test, providing evidence that retention (performance at test) is best when conditions (task or context) are the same at learning and test; we will call such an interaction a "matching effect." Verbal retrieval is facilitated when the external environment at learning is reinstated at test (Baddeley, Cuscaro, Egstrom, Weltmen, \& Willis, 1975; Smith, Glenberg, \& Bjork, 1978) or when a subject's internal state is the same at learning and test (Eich, 1989). The encoding-specificity work of Tulving and Thomson (1973) showed that the verbal cues that were presented during learning crucially determined which cues would be most effective at test. Within the transfer-appropriate processing (TAP) framework, Morris, Bransford, and Franks (1977) and Bransford, Franks, Morris, and Stein (1979) provided evidence that verbal recognition performance was best when the task at test was similar to the task at learning.

Such interaction effects cast doubt upon claims of simple effects of factors during learning, suggesting that the apparent effects of factors during learning were in fact dependent on the particular test conditions. For example, Morris et al. (1977) argued that the results of Craik and Lockhart (1972) were due to the retrieval test being more similar to the "deep" (semantic) orientation task than to the "shallow" processing task, and provided evidence that performance in the rhyming encoding condition of Craik and Lockhart was superior when the test 
also emphasized rhyming. Similarly, Lee and Hirota (1980) and Lee (1982) argued that memory for passive movements improves when the test involves passive recognition; Lee (1988), Marteniuk and Rodney (1979), and Wright and Shea (1991) provided additional evidence for matching effects in motor learning.

These issues have also arisen in research on the effects of perceptual feedback on learning. Motor learning appears to be strongly facilitated by the availability of feedback (alternatively, knowledge of results ${ }^{1}$ ) during learning (Adams, 1971; I. M. Bilodeau, 1966; Schmidt, 1975). Salmoni, Schmidt, and Walter (1984) observed that "information provided by the sense organs-usually termed feedback -is almost without dispute considered critical for learning new motor actions" (p. 356). However, the apparent facilitating effects of visual feedback on motor learning appear to be dependent on feedback conditions at test. Subjects trained in an aiming or linear positioning task with visual feedback (view of the moving limb) performed worse than subjects who learned without visual feedback if the test condition did not include visual feedback (Adams, Goetz, \& Marshall, 1972; Elliot \& Jaeger, 1988; Proteau \& Cournoyer, 1990; Proteau, Marteniuk, Girouard, \& Dugas, 1987; Proteau, Marteniuk, \& Levesque, 1992). In addition, subjects who learned without visual feedback were actually impaired when they were tested in a condition in which visual feedback was present (Adams et al., 1972; Elliot \& Jaeger, 1988; Proteau et al., 1992). Proteau et al. (1987; Proteau et al., 1992) proposed that practice under a given feedback condition creates an integrated sensorimotor representation (combining central processes and sensory feedback) that is highly specific to the learning conditions; any change in the conditions at test will then cause impaired performance.

There is thus a prevailing view in both verbal memory and motor learning that memory is enhanced when conditions (task or context) are similar during learning and during a later test of retention, and some skepticism about whether encoding effects can be described independently of retrieval conditions.

The present article addresses these issues in the domain of music performance, using the presence or absence of auditory feedback as the contextual manipulation. Instrumental music performance is an interesting area for addressing such learning and memory questions. It shares some important features with spoken language (the production of ordered sequences with hierarchical structure, the requirement for precise sequence timing, and the central role of the auditory modality) and also shares features with tasks used in motor learning (movements of the hands and fingers, and absence of a verbal component). From a listener's perspective, music is a complex structured sequence of sounds, but from a performer's perspective, it is also a long, complex sequence of motor acts. When a musician performs from written music, the sequencing of finger movements is largely specified by the notation, but music performance often takes place from memory. Memorized music perfor- mance is an extreme form of serial recall, and preparing music for memorized performance is a demanding task (Chaffin \& Imreh, 1997). A professional pianist in a classical solo recital may need to perform many thousands of notes accurately from memory for $60 \mathrm{~min}$ or more, with little room for error.

One question involves the role of sound during music performance (for ease of exposition, the terms sound and auditory feedback will be used interchangeably in this article). Music performance involves a number of sources of perceptual information, including auditory information available in sounded feedback, kinesthetic information available from motor movements, visual information about hand position, and visual information available from music notation. Auditory information is particularly relevant: Production of sound is the goal of music performance, and sound is an almost inescapable side effect of performance on a musical instrument. It thus seems plausible that auditory feedback might be essential to music performance, a hypothesis that matches the intuition of many musicians. Experimental studies have shown that feedback alterations (e.g., delayed auditory feedback) can impair music performance (Finney, 1997; Gates \& Bradshaw, 1974; Havlicek, 1968), and musicians must often consciously adjust to altered feedback when performing in reverberatory performance halls where delays can occur between production and perception.

However, theoretical and empirical studies have suggested that auditory feedback is in fact not essential to music performance. Using the rapid rate of piano performance as his example, Lashley (1951) argued that fast movement sequences could not be controlled by chaining of responses based on feedback, and investigations of the role of auditory feedback in music performance (using electronic keyboards) have shown little or no effect of its absence. Finney (1997) found no significant effects of auditory feedback removal on errors, dynamics, or timing, extending the findings of Gates and Bradshaw (1974) and Banton (1995). Repp (1999) reported small (although statistically significant) effects of feedback absence on variables of expressive performance, but concluded that (except for pedaling) there were "no serious disruptive effects" (p. 435) of auditory feedback removal. The existing literature thus documents little effect of auditory feedback removal on music performance. However, all these studies have involved performance from music notation. Auditory feedback might be unnecessary in such a stimulus-driven task but could play a more important role in forms of music performance not involving notation. For example, in memorized music performance (when the to-be-performed sequence is not specified by a visual stimulus), other forms of information such as auditory feedback might become critical (Finney, 1997). However, Repp (1999) has suggested that pianists playing highly rehearsed and memorized repertoire might be impaired very little by feedback removal. We address this question in the present work. 
Our central question involves the role of auditory feedback in music learning. Even if sound is not necessary for an adequate level of performance in music, it might be important for learning or recall. In the closedloop theory of Adams (1971) and Adams and Bray 1970), perceptual feedback during learning is important in both the verbal and motor domains; perceptual feedback is also important in the schema theory of Schmidt (1975). These proposals suggest that auditory feedback will be important for music learning (a claim explicitly made by Repp, 1999). In addition, a number of studies have shown that learning and memory in skilled music performance involve auditory-based conceptual (structural) dimensions such as pitch, tonality, harmony, meter, and melodic structure. Skilled adult pianists' ability to learn new music is based on conceptual dimensions related to auditory features of pitch and melody (Palmer \& Meyer, 2000). In performance, skilled musicians tend to produce confusion errors that reveal interactions among elements that share pitch or temporal structure, such as diatonically or harmonically related errors (Drake \& Palmer, 2000; Palmer \& Drake, 1997; Palmer \& van de Sande, 1993, 1995; see also Repp, 1996). Although several of these studies are based on sight-reading tasks rather than performance from memory, these findings suggest that skilled musicians encode and remember music in terms of auditory attributes such as pitch and duration. Auditory feedback during learning might contribute to the formation of a representation that incorporates auditory information; however, the use of such a representation at retrieval might be affected by the availability of auditory information at test. We manipulated feedback conditions at both learning and test to address this possibility.

Finally, we investigate domain-specific interference effects on serial position curves for recall of music. Serial recall of verbal materials typically shows a bow-shaped serial position curve, and this has been replicated with musical materials (Deutsch, 1980; Roberts, 1986; Roberts, Millen, Palmer, \& Tartter, 1983). Musicians' written serial recall of randomized sequences of musical tones or chords indicated increased accuracy in primacy and recency portions of the serial position curve (Roberts, 1986). Interpolated material between presentation and recall impaired the recency portion more than the primacy portion. One issue is whether these findings are limited to written serial recall, or whether they would obtain in a music performance task. Another issue is whether serial recall of natural melodies shows constraints similar to those obtained with randomized tone sequences (Roberts, 1986). Musical sequences contain probabilistic constraints on the serial ordering of pitches, with beginning and ending pitches being more highly constrained or stylized (see Piston, 1987). We address these issues by testing effects of different interpolated tasks (including auditory, motor, and arithmetic tasks) on the serial position curve for recall of music performance.

We report three experiments that address the role of contextual information provided by auditory feedback in music learning and performance. Experiments 1 and 2 used a learning/test paradigm in which pianists learned unfamiliar musical pieces from notation and were then tested on their ability to play the pieces from memory. In Experiment 1, we tested whether auditory feedback during learning improved later recall and also examined the extent to which this interacted with auditory feedback conditions at test. In Experiment 2 we added motoric and auditory music interference tasks between learning and test (as well as an arithmetic control condition) to compare the roles of auditory and motoric information. In Experiment 3 we investigated the role of auditory feedback in more naturalistic performance conditions: welllearned memorized performances of long and complex musical sequences.

\section{EXPERIMENT 1}

In Experiment 1, the availability of auditory feedback was manipulated at both learning (performance from notation) and test (performance from memory). If feedback during learning facilitates memory, performance at test should be superior for conditions in which sound is present during learning as opposed to when it is absent. A second question is the extent to which recall is improved when feedback presence or absence is matched during learning and test.

\section{Method}

Subjects. Sixteen adult pianists (mean age 21.7 years, ranging from 18 to 44) from the Columbus, Ohio, community participated in the experiment. They had a mean of 9.9 years of piano instruction (range $=5-16$ ), and they had played piano for a mean of 13.6 years (range $=6-34$ ). They received either course credit or payment for their participation.

Equipment. The pianists performed on a Roland RD600 electronic keyboard with weighted keys and a sampled piano timbre (Full Grand 3). They listened to their performances through AKG K270 headphones, with the volume level adjusted to their preference. Keystroke data were collected on a Gateway PC using the Cakewalk MIDI sequencer program. Auditory feedback was manipulated by connecting or disconnecting the pianists' headphones. The closed-earpiece headphones were worn in all conditions; this minimized (but did not necessarily eliminate) physical key noise from the keyboard.

Stimulus materials. The stimuli were four short two-part musical pieces in 4/4 meter, adapted for the experiment from early Baroqueera organ works. The pieces were two measures long and consisted of 23 notes (individual tones), distributed approximately evenly across the left and right hands. Each piece formed a complete musical phrase. Two of the stimuli were in major keys (C and $\mathrm{G})$, and two in minor keys (Am and Dm); an example is shown in Figure 1. A fifth musical piece containing only 10 notes was used to acquaint pianists with the experimental procedure. All pieces were unfamiliar to all of the pianists.

Design. The experimental design was a $2 \times 2$ within-subjects factorial combination of two levels of auditory feedback during learning (presence or absence) crossed with two levels of auditory feedback (presence or absence) during the subsequent test phase. The independent manipulation of auditory feedback at learning and test follows the orthogonal design suggested by Tulving (1979) for testing the interaction effects of context at learning and test, and is 


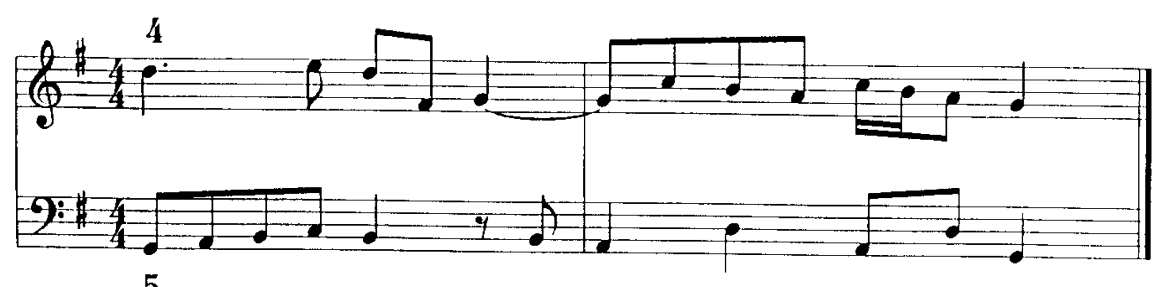

5

Figure 1. Experiment 1: Sample musical stimulus (numbers specify initial fingering).

equivalent to the double-transf er design that Schmidt and Lee (1999) and Proteau (1992) have recommended for distinguishing variables that affect learning from those that affect performance. A within-subjects design was used to control for the range of performer skill levels. Each pianist performed in all four conditions, with a different musical stimulus in each condition. Ordering of conditions, assignment of musical stimulus to condition, and ordering of pieces were fully counterbalanced across pianists.

Procedure. Pianists were tested individually. They were told that they would first perform music from notation and then perform it without the notation to see how well they remembered it. The procedure for each of the four conditions thus involved a learning phase and a test phase. The subjects were informed at the start of each phase as to whether they would hear their performance over the headphones. Pianists chose their own tempi, and they were instructed to to emphasize accuracy rather than speed. They were required to perform the piece each time from beginning to end without stopping to correct errors. To acquaint the pianists with the procedure, we directed them to perform a short practice piece five times from notation (with sound), and then to perform it three times from memory (with sound). At the start of each experimental condition, the pianists were given the musical notation to study for as long as they wished before performing (typically 30-60 sec). They then performed the piece 10 times from the notation, pausing for a few seconds between performances. The experimenter told the pianists when the 10 performances were completed; the musical notation was then removed and the pianists performed the piece from memory four times. This procedure was repeated for each of the four conditions.

\section{Results}

The dependent variable was the percentage of total pitch events in each performance that were in error. Errors were identified by computer comparison of each performance with the pitch contents of a notated score (see Large, 1993; Palmer \& van de Sande, 1993, for details). Correction errors (an error in which two or more consecutive events were performed incorrectly and then restarted correctly; see Palmer \& Drake, 1997) were removed from the analysis because they represented nonindependent errors; they formed $4 \%$ of the total errors. In addition, any consistent error that occurred in 7 or more of the 10 learning trials was assumed to be an error in reading the notation and was removed from the analysis of both learning and test trials (see Palmer \& van de Sande, 1993); 8\% of the total errors were removed for this reason.

Subjects' performances improved during the learning trials but were not affected by feedback. A two-way analysis of variance (ANOVA) was conducted on the error percentages by learning trial (10) and experimental condition (sound present/absent). Pianists improved over the sequence of 10 learning trials $\left[F(9,135)=4.48, M S_{\mathrm{e}}=\right.$ $0.0021, p<.001]$. There was no significant effect of sound (presence or absence) on performance during the learning trials $\left[F(1,15)=.32, M S_{\mathrm{e}}=0.001, p=.58\right]$ and no sound $\times$ trial interaction $\left[F(9,135)=.33, M S_{\mathrm{e}}=\right.$ $0.001, p=.96]$. Removal of auditory feedback did not affect performance when notation was present.

Accuracy on the recall test was computed for each performer as the difference between the mean pitch error percentage in the four test trials and the mean of the last four learning trials; the mean difference scores across pianists are shown in Figure 2. Performance on the test trials was better when learning occurred with sound, and this effect occurred regardless of conditions at test. A two-way ANOVA on the difference scores was performed, with conditions during learning (sound present/absent) and conditions during test (sound present/absent) as factors. The presence of sound during learning had a significant effect $\left[F(1,15)=24.87, M S_{\mathrm{e}}=0.0081, p<\right.$ $.001]$, with better performance at test when sound was present at learning than when it was absent. Fifteen of 16 subjects showed better recall when sound was present at learning ( $p<.01$, binomial sign test). The main effect of sound at test was not significant $[F(1,15)=.23$, $\left.M S_{\mathrm{e}}=0.019, p=.64\right]$, nor was the interaction between sound presence at learning and at test $[F(1,15)=1.10$, $\left.M S_{\mathrm{e}}=0.017, p=.31\right]$. Auditory feedback during learning had a significant effect on later recall, but the presence or absence of auditory feedback at test did not affect recall, nor did auditory feedback affect performance during the learning phase itself.

Performance at test was also examined by serial position within each musical sequence; the dependent variable was the percentage of pitch events performed correctly at each position. For these analyses, one or two middle events were removed from the longer pieces to normalize the number of serial positions across sequences to 14 (although all stimuli contained 23 notes, the number of sequence positions ranged from 14 to 16 events; a given sequence position could contain either one or two note onsets). Accuracy scores at each serial position for the test trials in Experiment 1 are shown in Figure 3 by learning condition, combined across test conditions. An ANOVA on the percent correct events in each performance by serial position (14), sound at learning (present/absent), and sound at test (present/absent) yielded a significant main effect of sound at learning 


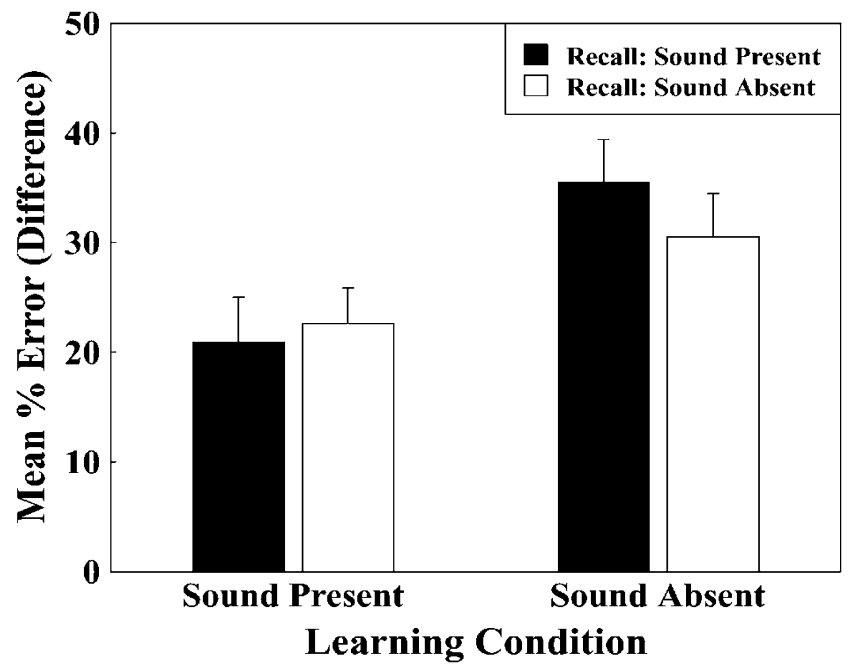

Figure 2. Experiment 1: Mean percent error at test, computed as the difference between the mean error on the four test trials and the mean error on the last four learning trials. Bars indicate standard error.

$\left[F(1,15)=21.7, M S_{\mathrm{e}}=0.23, p<.01\right]$. Accuracy was higher at test when sound was present at learning than when it was absent.

There was also a significant main effect of serial position $\left[F(13,195)=10.2, M S_{\mathrm{e}}=0.09, p<.01\right]$. As shown in Figure 3, accuracy at test was highest in the primacy portion of the curve and next highest in the recency portion. Again, there were no effects of sound presence/ absence at test $\left[F(1,14)=.004, M S_{\mathrm{e}}=0.57\right]$ nor any interaction $\left[F(1,14)=1.14, M S_{\mathrm{e}}=0.47\right]$. The same ANOVA repeated on only the first four (primacy) and last four (recency) serial positions indicated that accu- racy was higher in the primacy portion than in the recency portion $\left[F(1,15)=5.53, M S_{\mathrm{e}}=0.07, p<.05\right]$. Thus, the serial position data replicated the advantage of sound present at learning across all sequence positions. The serial position findings also replicate the basic primacy and recency curves found in tests of verbal recall.

\section{Discussion}

Experiment 1 demonstrated that the presence of sound during learning aided later recall of music. Absence of auditory feedback did not affect the error rate during the learning trials themselves, consistent with previous find-

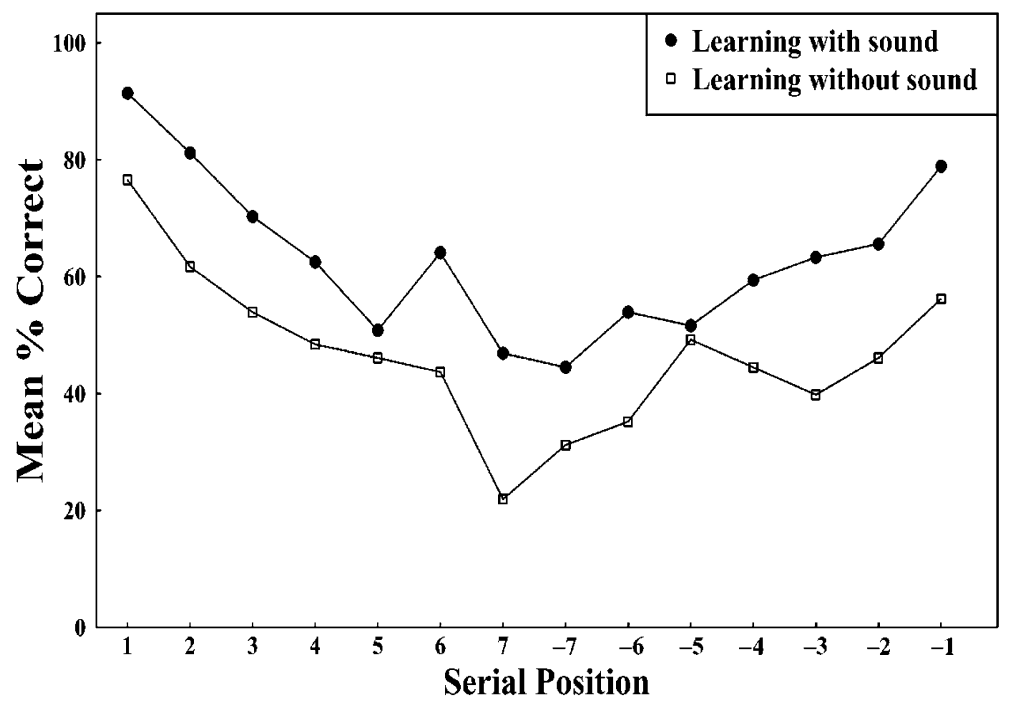

Figure 3. Experiment 1: Mean percent correct at test by serial position and learning condition, collapsed across test conditions. 
ings on music performance from notation (Banton, 1995; Finney, 1997; Gates \& Bradshaw, 1974; Repp,1999). There was no effect of sound at test (auditory feedback was not important during recall), nor was there a significant interaction involving sound at learning and sound at test. The facilitating effect of auditory feedback was not simply due to matching of auditory feedback conditions during learning and test.

Auditory feedback at learning facilitated memory across all serial positions. Primacy and recency effects were obtained for musical events in performance, confirming and extending previous findings of primacy and recency effects for written recall of randomized musical materials (Deutsch, 1980; Roberts, 1986; Roberts et al., 1983). These results suggest that memory for complex musical sequences in a performance task reflects the same serial constraints as for simpler materials recalled in a written task. The serial position results also provide converging evidence for the importance of sound at learning on later recall; the effects occur across all portions of the serial position curve.

\section{EXPERIMENT 2}

Experiment 2 used an interference paradigm to address whether auditory information is part of the memory representation or simply facilitates the formation of a nonauditory representation (such as a motoric one; Palmer \& Meyer, 2000). We tested whether motoric or auditory interference between learning and test influenced recall of music. Modality-specific interference effects have been demonstrated for recall of verbal and spatial information (Brooks, 1968); furthermore, music (but not white noise) has been shown to cause interference with recall of verbal material (Salamé \& Baddeley, 1989), suggesting that cross-domain interference can occur within the same (auditory) modality. In Experiment 2 , four intervening interference tasks were contrasted between learning and test: an auditory-only task (hearing music, but making no movements), a motoronly task (performing from musical notation, but without sound), a combined auditory-motor task (normal music performance), and an arithmetic task (counting aloud to prevent mental rehearsal). Auditory feedback was present during learning for these four conditions. Experiment 2 also contained a replication condition in which learning occurred in the absence of auditory feedback (as in Experiment 1), but with an arithmetic interference task before recall. Comparison of the replication condition with the arithmetic interference condition allows a test of whether the facilitating effects of auditory feedback at learning extend to delayed recall conditions with an intervening task.

\section{Method}

Subjects. Twenty-four adult pianists (mean age 20.3 years, ranging from 18 to 32 ) from the Columbus, Ohio, community partici- pated in the experiment. They had a mean of 10.7 years of piano instruction (range $=4-15$ ), and they had played piano for a mean of 12.9 years (range $=4-20$ ). They received either course credit or payment for their participation. None of the pianists had participated in Experiment 1.

Equipment and stimulus materials. The same equipment was used as in Experiment 1, except that data were collected using the FTAP program (Finney, 2001), which allowed the pianist's auditory feedback to be turned off without physically unplugging the headphones. The same musical stimuli were used as in Experiment 1, except that the stimulus with the lowest error rate was altered slightly to equate it in difficulty with the other stimuli. A new musical stimulus was created for use in the replication condition, following the same constraints used for the original four pieces. Four musical exercises, two in major key and two in minor key, were created for use as interference stimuli. The interference stimuli were all in 4/4 meter and contained 32 sixteenth notes; they were designed to require the use of all fingers on each hand in an unpredictable pattern.

Design. A within-subjects learning/test paradigm was used (as in Experiment 1), with an added interference task between learning and test. Four types of interference conditions (sound, motor, sound-plus-motor, arithmetic) were created in which auditory feedback was present at both learning and test. In the fifth (replication) interference condition, auditory feedback was absent during learning and was followed by an arithmetic interference task and the recall test (with auditory feedback present and music notation absent). Counterbalancing assignments of musical stimuli and conditions for the first four conditions were the same as in Experiment 1 . The replication condition (learning without sound) was always the last condition of the experiment, and the same stimulus was used in this condition for all subjects; this was necessary to maintain full counterbalancing in the first four conditions. An experimental stimulus in a major key was always matched with an interference stimulus in a minor key, and vice versa, to avoid confusion among memory and interference stimuli.

Procedure. The procedure was similar to that of Experiment 1, but with the addition of an interference task. Subjects practiced two sequences at the start of the experiment, with auditory feedback present during learning and test. For the first practice sequence, pianists performed the musical piece from notation for five learning trials and then from memory for three test trials. For the second practice sequence, an arithmetic interference task was added between learning and test.

In each experimental condition, pianists performed the music 10 times from the notation at their own pace. The experimenter then informed the pianists about the interference task they would be performing, and the pianists were given musical notation for the musical interference conditions or written arithmetic instructions for the control condition. In the sound-only musical interference condition, pianists listened to a performance of one of the musical exercises (which was sounded twice at a moderate tempo); they were instructed to follow along on the corresponding musical notation but not to move their fingers. In the motor-only musical interference condition, pianists performed the musical exercise on the keyboard but were not able to hear themselves. In the sound-plus-motor musical interference condition, pianists performed the musical exercise and heard their performance. The arithmetic condition involved simple adding (e.g., "count aloud from 99 by $4 \mathrm{~s}$ "), intended to block mental rehearsal but have no musical content. In the replication condition, pianists learned the music without auditory feedback, performed the arithmetic interference task, and then performed the music from memory. All interference tasks were $15 \mathrm{sec}$ long; the total time between the end of learning and start of recall was approximately $45 \mathrm{sec}$. Each interference task was cued by a starting and ending piano tone. Because of the increased difficulty 


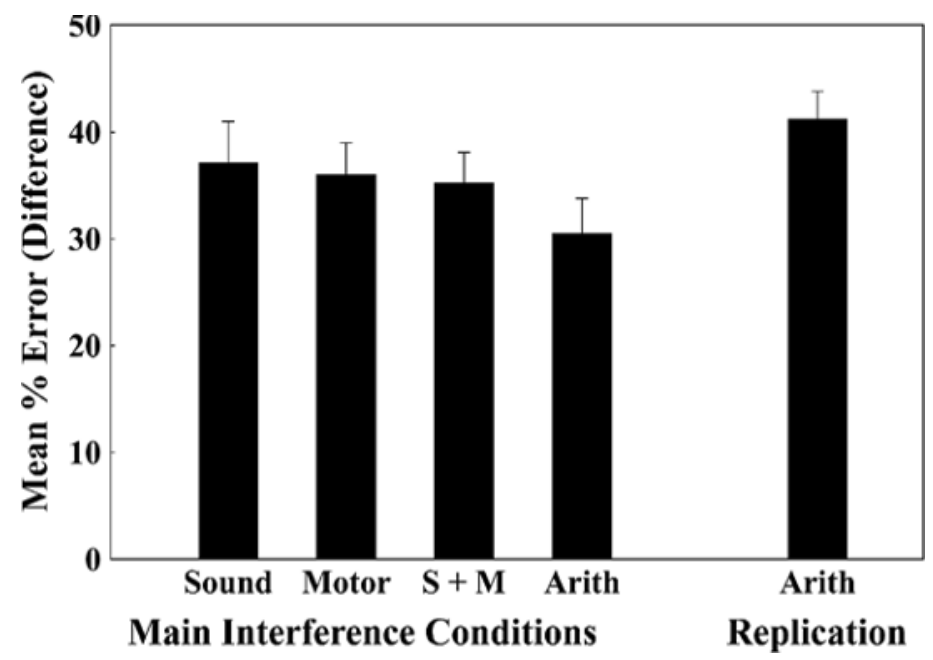

Figure 4. Experiment 2: Mean percent error at test, computed as the difference between the mean error on the four test trials and the mean error on the last four learning trials. The leftmost four conditions had sound (auditory feedback) during learning; the replication condition (right) did not. Sound was present at test in all conditions. " $S+M$ " indicates sound plus motor. Bars indicate standard error.

of the delayed memory task, pianists were given a cue sheet at recall that provided the initial chord of the music.

\section{Results}

As in Experiment 1, correction errors (3\% of the total errors) and learning errors (5\% of the remaining errors) were removed from the analyses. Accuracy at recall was measured in difference scores from learning to test, as in Experiment 1; the data are shown in Figure 4. Overall difference scores were worse (mean $=36 \%$ errors) than in Experiment 1 (mean $=27 \%)$, reflecting the increased difficulty of the interference tasks. Although the difference scores across the four main interference conditions did not differ significantly $\left[F(3,69)=1.22, M S_{\mathrm{e}}=\right.$ $0.017, p=.31$ ], arithmetic interference impaired recall significantly less $($ mean $=30 \%)$ than the mean of the three musical interference conditions (mean $=36 \%$ ), planned comparison $\left[F(1,23)=7.08, M S_{\mathrm{e}}=0.0054\right.$, $p<.05]$. Sixteen of 24 subjects had worse interference from music than from arithmetic, with two ties (binomial sign test, $p<.01)$.

The replication condition (learning without sound, arithmetic interference) showed more impairment at test (mean $=41 \%)$ than the arithmetic interference condition in which sound was present during learning (mean = $30 \%)$; the difference between the two conditions was significant $[t(23)=3.80, p<.001]$. Sixteen of 24 subjects had better recall when sound was present during learning than when it was absent (binomial sign test, $p<.01$ ). To facilitate comparison of the feedback-absence effect with that of Experiment 1 ( $n=16$ subjects), the same analysis was repeated for the first 16 subjects in Experiment 2; the finding was still significant $[t(15)=3.14, p<.01]$. Sound during learning again facilitated later recall.

Because the replication condition always occurred at the end of the experiment and always involved the same stimulus, one legitimate concern is whether the effect might be due to condition ordering or stimulus. However, there were no significant effects of condition order in Experiment $1[F(3,45)=0.64, p=.59]$ or in the first four conditions of Experiment $2[F(3,69)=1.62, p=$ .19]. Furthermore, error percentages during the learning trials in the sound-absent replication condition in Experiment 2 (mean $=2.5 \%$ ) were not significantly different from those in the sound-absent learning trials of Experiment $1($ mean $=2.9 \%)[t(54)=0.53, p=.58]$, suggesting that differences in stimulus materials were not responsible for the effect.

Serial position effects. The percentages of pitch errors at each serial position in the musical sequences are shown in Figure 5 (averaged across the three musical interference conditions). As in Experiment 1, sequences longer than 14 positions were shortened in middle positions for comparison. Percent recall at the first serial position was near perfect due to the pianists' cue for the first chord of the sequence. For comparison, the serial position curve for the corresponding condition in Experiment 1 , in which sound was present at learning and at test (with no interference), is also shown. The percent correct scores for the four main experimental conditions yielded significant effects of serial position $[F(12,276)=$ $\left.14.0, M S_{\mathrm{e}}=0.09, p<.01\right]$, with highest accuracy in the primacy and recency portions of the curve. There were no significanteffects of condition $\left[F(3,69)=0.89, M S_{\mathrm{e}}=\right.$ 


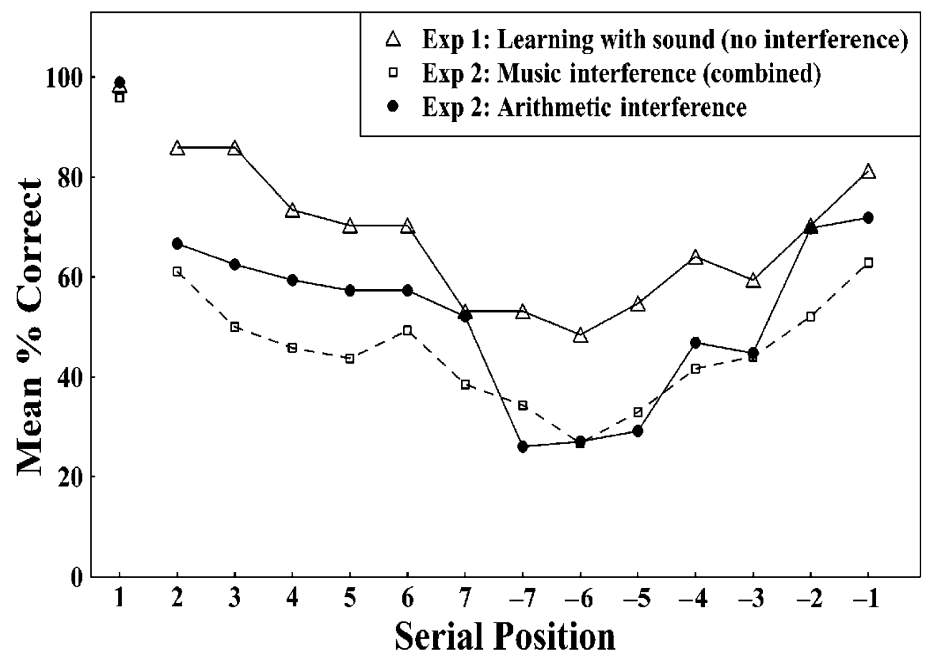

Figure 5. Experiments 1 and 2: Mean percent correct at test, based on serial position.

$0.51]$ or interactions with serial position $[F(36,828)=$ $\left.0.68, M S_{\mathrm{e}}=0.10\right]$. The same ANOVA contrasting the arithmetic interference condition with the three music interference conditions combined also indicated a main effect of serial position $\left[F(12,276)=12.40, M S_{\mathrm{e}}=0.06\right.$, $p<.01]$ and a main effect of condition $[F(1,23)=4.20$, $\left.M S_{\mathrm{e}}=0.16, p=.05\right]$. As shown in Figure 5, recall following the arithmetic interference condition was significantly more accurate across most serial positions than recall following the musical forms of interference.

The accuracy measures for the two arithmetic interference conditions (with and without sound at learning) by serial position are shown in Figure 6. The absence of sound at learning decreased accuracy overall $[F(1,23)=$ $\left.19.50, M S_{\mathrm{e}}=0.33, p<.01\right]$. There was also a main effect of serial position $\left[F(12,276)=12.20, M S_{\mathrm{e}}=0.10, p<\right.$ $.01]$ and an interaction between sound present/absent during learning and serial position $[F(12,276)=2.72$, $\left.M S_{\mathrm{e}}=0.10, p<.01\right]$. As shown in Figure 6, the absence of sound at learning decreased accuracy most in the primacy and recency portions of the curve. Thus, the impairing effects of removing auditory feedback during learning were replicated in serial position curves under conditions when recall was delayed.

\section{Discussion}

Performers' memory for music was better when learned in the presence of auditory feedback even when a task that delayed recall and prevented rehearsal intervened between learning and test. The facilitating effect of auditory information at learning found in Experiment 1 was robust across the short filled intervals of Experiment 2. Music interference conditions caused worse recall than arithmetic interference across the serial position curve. In comparison with the cross-domain, within-modality interference of music in verbal serial recall (Salamé \& Baddeley, 1989), these findings suggest domain-specific interference effects for music and verbal material (see also Roberts, 1986). However, the degree of interference is often related to stimulus complexity in serial recall (Baddeley \& Hitch, 1994), and the auditory and visual complexity of the musical stimuli may have been greater than that of the arithmetic stimuli. Nevertheless, the encoding effect of auditory feedback at learning found in Experiment 1 was robust across different performers, delayed recall conditions, and an intervening task.

\section{EXPERIMENT 3}

In Experiment 3 we investigated whether auditory feedback affected the recall of more complex, welllearned music. This addressed two issues. First, Adams, Gopher, and Lintern (1977) and Proteau et al. (1987) have demonstrated that the importance of (visual) feedback can increase with practice, with more extensive practice with feedback leading to a greater degree of impairment when it is removed at test. One possible explanation for the lack of an effect of feedback during recall in Experiment 1 is that the 10 learning trials were not sufficient to establish dependence on feedback. Memorized performance of well-learned music (practiced extensively under normal sound-present conditions) might be severely impaired in the absence of sound. Second, long musical pieces provide a more demanding test of the role of auditory feedback in memorized performance. Although the results in Experiment 1 showed no significant effect of auditory feedback removal on errors in memorized performance, the pieces used were short and novel. The increased demands of performing long pieces might induce more reliance on the auditory information provided by feedback.

In this experiment, pianists chose musical pieces from their existing repertoire and performed them from memory under both sound-present and sound-absent conditions. 


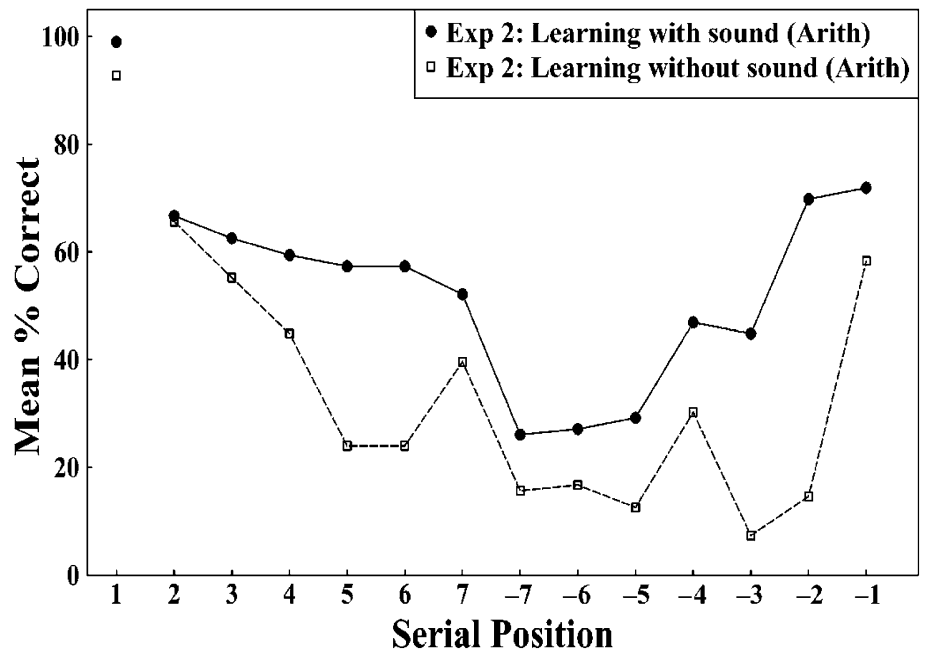

Figure 6. Experiment 2, arithmetic interference (replication) conditions: Mean percent correct at test, based on serial position.

Accuracy of the performances was again measured in terms of pitch errors. In addition, the types of errors were evaluated; previous work (Palmer \& Drake, 1997; Palmer $\&$ van de Sande, 1993) has shown that errors in music performance tend to reflect similarity-based confusions among elements that have similar structure (such as diatonically related pitches from the key of the musical sequence). Although Palmer and van de Sande (1993) and Palmer and Drake (1997) suggested that the influence of similarity occurs at the retrieval or planning level, it is possible that it is influenced by the performer's auditory perception of tonality, which arises from the sounded performance. To address this, we tested whether diatonically related errors occurred more when auditory feedback was present than when it was absent (consistent with a dependence on sound), or whether they were independent of feedback and reflect basic retrieval (planning) errors, as previously suggested (Palmer \& van de Sande, 1993).

\section{Method}

Subjects. Eleven skilled adult pianists (mean age 24.2 years, ranging from 18 to 40 ) from the Columbus, Ohio, community participated in the experiment. They had a mean of 11.8 years of piano instruction (range $=8-20$ ), and they had played piano for a mean of 15.2 years (range $=10-30$ ). They received either course credit or payment for their participation. Two of the participants performed two different pieces; each piece was treated independently in the statistical analyses.

Most of the participants in Experiment 3 had come to the laboratory for a different experiment. Afterward, they were asked if there were any musical pieces they knew from memory; if so, they were asked to participate in Experiment 3. The participants had not been asked in advance to prepare a memorized piece. One of the participants had participated in Experiment 1, and 3 had participated in Experiment 2.

Equipment. The equipment was identical to that used in Experiments 1 and 2. Keyboard data were collected with either the Cakewalk sequencer program or the FTAP program (Finney, 2001).
Stimulus materials. The memorized music covered a wide range of length and difficulty; Table 1 provides information on the musical pieces performed. In some cases, pianists did not play a complete piece and, for technical reasons, analyses of two additional pieces were conducted on just an initial portion of the performances. The analyzed portions ranged from 166 to 1,512 individual notes, and the mean duration of the analyzed portions of the performances was $115 \mathrm{sec}$ (ranging from 23 to 290).

Design and Procedure. Pianists performed a musical piece of their own choice that they knew and could play from memory. After they performed the piece (without notation, but with auditory feedback) to their satisfaction, they were asked to perform it again without auditory feedback. Because there had been no preparation for these memorized performances prior to the experiment, the pianists always performed in the normal sound-present condition first. Although practice effects due to this ordering might have increased pianists' ability to perform the pieces without auditory feedback (thus underestimating the true error rate in the feedback absent condition), we felt that it was necessary to have a natural context for pianists' initial recollection of the piece (see also Repp, 1999).

\section{Results}

Pitch errors were again identified by computer; correction errors were removed from the analysis, as in Experiments 1 and 2. Errors that occurred in both performances of a piece were also removed from the analyses; such consistent errors (e.g., omitting a repeat or misplaying an accidental) may be due to incorrect learning of a piece rather than recall errors. In addition, permissible performance variants from the notation (e.g., performer-specific decisions on notated ornaments or trills), as well as immediately surrounding notes, were excised from the analyses (they were also removed from the total note count used in the error rate calculation, as listed in Table 1). Error percentage was computed as number of errors divided by number of total notes in the piece; the results are shown in Table 1. The total times (duration from first event to last event) of the performances are also provided. 
Table 1

Experiment 3: Error Percentages and Elapsed Times for Memorized, Well-Learned Performances, With and Without Sound (Auditory Feedback)

\begin{tabular}{|c|c|c|c|c|c|c|c|}
\hline \multirow[b]{2}{*}{ Pianist } & \multirow[b]{2}{*}{ Piece } & \multirow[b]{2}{*}{ \# Notes } & \multirow[b]{2}{*}{ \# Measures } & \multicolumn{2}{|c|}{ Error $(\%)$} & \multicolumn{2}{|c|}{ Duration $(\mathrm{Sec})$} \\
\hline & & & & Sound & No Sound & Sound & No Sound \\
\hline 1 & Bach Em Toccata & 166 & 13 & 0.0 & 0.0 & 35.2 & 33.9 \\
\hline 2 & Bach Cm Fugue & 754 & 31 & 0.9 & 0.8 & 115.6 & 113.4 \\
\hline $3 \mathrm{a}$ & Bach Italian Concerto (I) & 1,310 & 111 & 3.4 & 4.3 & 134.2 & 134.8 \\
\hline $3 b$ & Beethoven Sonata (II) (Pathétique) & 1,512 & 73 & 3.6 & 4.8 & 281.6 & 290.0 \\
\hline 4 & Mozart CM Sonata (I) & 185 & 11 & 1.6 & 3.8 & 23.1 & 23.3 \\
\hline $5 \mathrm{a}$ & Beethoven Sonata (II) (Pathétique) & 1,512 & 73 & 5.4 & 5.0 & 246.1 & 248.5 \\
\hline $5 b$ & Bach B`M Prelude & 322 & 20 & 2.5 & 2.8 & 29.5 & 29.6 \\
\hline 6 & Beethoven Sonata (II) (Pathétique) & 1,166 & 56 & 5.7 & 6.6 & 197.7 & 192.4 \\
\hline 7 & Rachmaninoff Prelude & 468 & 14 & 1.9 & 2.3 & 77.7 & 80.0 \\
\hline 8 & Bach Dm Invention & 285 & 42 & 6.3 & 4.6 & 52.6 & 48.4 \\
\hline 9 & Beethoven, Für Elise & 1,022 & 125 & 2.1 & 1.5 & 143.3 & 146.3 \\
\hline 10 & Bach Cm Prelude & 1,081 & 33 & 2.1 & 1.3 & 92.3 & 91.3 \\
\hline 11 & Stravinsky Andantino & 184 & 20 & 1.1 & 2.7 & 62.0 & 64.8 \\
\hline Mean & & & & 2.8 & 3.1 & 114.7 & 115.1 \\
\hline
\end{tabular}

Note-Roman numerals in parentheses are movement numbers.

Error percentages were low (mean $=2.97 \%$ ) despite the length and complexity of the music and the lack of preparation. Errors were low both when sound was present $($ mean $=2.82 \%)$ and when it was absent (mean $=$ $3.12 \%$ ). A paired $t$ test on the error percentages for each performance, with auditory feedback presence/absence as the factor, was not significant $[t(12)=1.04, p=.32]$, nor was a paired $t$ test on the performance durations $[t(12)=0.46, p=.66]$. Inspection of Table 1 shows that there were more errors in the sound-absent condition than in the sound-present condition on only 7 out of 13 performances, well within the range of chance differences. Auditory feedback removal did not have a significant effect on memorized performance.

The types of errors produced in performances with and without sounded feedback were compared next. The proportion of diatonically related errors (errors whose pitch matched one of the seven pitch classes in the key of each musical piece) was computed for each performance (excluding Pianist 1, who made no errors in either condition). The mean proportions of diatonically related errors were .814 in the sound-present performances and .855 in the sound-absent performances. These proportions were compared with the chance estimate (7 out of 12 possible pitch classes, or .573, are diatonically consistent by chance with each musical key). The mean proportion of diatonically related errors was higher than expected by chance for both the sound-present performances $[t(11)=$ $3.76, p<.01]$ and the sound-absent performances $[t(11)=$ $6.17, p<.01]$, consistent with previous findings in welllearned piano performances (Palmer \& Drake, 1997; Palmer \& van de Sande, 1995). Next, a paired $t$ test was conducted to ascertain whether pianists made more diatonically related errors in performances with sound than without sound. The difference between conditions (with more diatonically related errors in the absence of sound, opposite to that expected) was not significant $[t(11)=$ $0.84, p=0.41]$. Analyses of error subtypes thus confirmed the analyses of overall error rates: Removal of auditory feedback did not affect performance. The errors appear to have been driven by retrieval or planning failures.

\section{Discussion}

Performances from memory of well-learned music showed little effect of removal of auditory feedback: Error rates were equally low in the presence and absence of sound. The hypothesis that extensive practice with feedback at learning would cause increased dependence on feedback at test was not supported. Furthermore, the types of similarity-based confusions seen in music performance did not change across the feedback conditions, consistent with explanations that such errors reflect retrieval rather than perceptual processes.

\section{GENERAL DISCUSSION}

We tested the hypothesis that auditory feedback might be an important contextual factor in memory for music performance by manipulating auditory feedback availability while pianists learned and then recalled novel musical sequences. Experiment 1 demonstrated a strong facilitating effect of auditory feedback during learning on later recall. However, auditory feedback during recall did not significantly affect performance, nor did sound affect performance during the learning trials themselves. Importantly, there was also no significant interaction between feedback conditions at learning and conditions at test. Experiment 2 replicated the facilitating effect of auditory feedback during learning in an interference paradigm in which recall was delayed and rehearsal was prevented. Furthermore, comparisons of musical and arithmetic interference indicated that music created greater interference. Finally, Experiment 3 demonstrated that removal of feedback did not impair the recall of longer, well-learned musical sequences. We discuss three aspects of these results in turn: the absence of an 
effect of auditory feedback during recall, the robust effect of feedback during learning on later recall (as well as serial position effects), and the absence of the expected interaction of conditions at learning and test.

Two general concerns should be addressed before discussing the results: statistical power and the use of sequencing errors as the dependent measure. With respect to the first point, we realize that experiments with more subjects might cause the small trend toward an encodingretrieval interaction seen in Figure 2 to be become significant. However, we anticipate that any such interaction would be small in comparison with the large and robust facilitating effect of sound during learning. Regarding the second point, errors in music performance are a fairly sophisticated measurement that incorporate both sequence memory and timing. However, it is possible that more continuous measurements (e.g., keystroke force) might show effects of feedback on learning that do not appear in our results (but see Finney, 1997; Repp, 1999).

\section{Auditory Feedback During Music Recall}

In Experiments 1 and 3, removal of auditory feedback during test did not significantly affect recall of the pieces, even in very demanding circumstances (in Experiment 3, some subjects performed continuously from memory for over $4 \mathrm{~min}$ ). This finding is inconsistent with Finney's (1997) suggestion that memorized performance would be impaired by auditory feedback removal and supports Repp's (1999) proposal that skilled memorized performance should be relatively unimpaired by auditory feedback removal. The absence of a feedback effect at recall is consistent with the view that memory for music performance is primarily motoric (see, e.g., Mainwaring, 1933), although the facilitating effect of auditory feedback during learning still requires an explanation.

\section{Auditory Feedback During Music Learning}

Auditory feedback during music learning improved later recall; we will term consider this an encoding effect. This finding is consistent with the general view that feedback or knowledge of results is important in learning, and confirms Repp's (1999) proposal that auditory feedback might be important for learning music. Importantly, this finding was established with an experimental design in which learning and test conditions were manipulated factorially, addressing the potential concern that such an encoding effect might simply be due to a confound involving the choice of task used at test.

We have not yet addressed the processes underlying the facilitating effect of auditory feedback on memory. Two types of explanation seem promising. The first is cognitive/conceptual in nature and emphasizes the role that sound might play in giving "meaning" to the performance task. It is generally accepted that meaningful stimuli are remembered better than irrelevant or nonmeaningful stimuli (see Crowder, 1976, for some discussion). Bartlett (1932) provided evidence that people tend to re- member what is important to them, and Craik and Lockhart (1972) argued that semantic processing leads to greater retention than perceptual processing. Bransford and Johnson (1972) provided evidence that recall of text has improved when subjects were given "appropriate prerequisite knowledge" beforehand, and Rubin-Rabson $(1937,1941)$ found that conceptual prestudy of music improved later memory. Sound in music performance might be necessary to make the initial learning task meaningful, perhaps by encouraging elaborations and conceptual or structural encodings (Craik \& Tulving, 1975; Eysenck, 1979; Jacoby \& Craik, 1979).

A second class of explanation is more perceptual in nature. Memory for stimuli may simply be better when there are multiple sources of sensory information about the to-be-learned stimulus (in the case of music, when auditory information is added to the motoric and visual information). James (1890) wrote approvingly of teaching children to read by a method "in which each word is impressed by the fourfold channel of eye, ear, voice, and hand" (p. 668), and Gibson (1969) argued for the importance of multimodal information and invariants during perceptual development. Such a multimodal hypothesis seems plausible, but there is little work in adult learning that can be unambiguously interpreted as support for it. For example, although Murray (1965) reported that adding auditory information to visually presented verbal stimuli improved memory, this may simply be a demonstration of the superiority of auditory presentation over visual presentation of verbal material reported by Mowbray and Gebhard (1958), Murray et al. (1999), and Penney (1989). Although such an auditory dominance effect is a potential explanation for the music findings as well (performing music with sound effectively creates an auditory representation of the stimulus), one important difference between language and music complicates such a proposal. For language users, hearing or seeing a word is usually sufficient for immediate (motoric) production of that word. However, for most instrumental musicians, simply hearing a melody is typically not sufficient for error-free performance of that melody. Either a cognitive or a perceptual explanation would be consistent with our results.

Serial position effects in recall of music provided converging evidence for the facilitating effects of auditory feedback at learning. Primacy and recency effects were obtained both in the absence (Experiment 1) and presence (Experiment 2) of intervening interference. Enhanced recall in primacy and recency portions extends earlier findings with random sequences of musical tones (Roberts, 1986) and indicates that general memory mechanisms are at work in music performance. Furthermore, musical interference in Experiment 2 caused more impairment across the serial position curve than did arithmetic interference. This finding is consistent with sensory-specific explanations of interference. However, both music and arithmetic interference impaired recall in primacy and recency portions, contrary to Roberts's 
(1986) finding of most impairment in recall of musical material at the recency portion. Many task differences could account for this difference. Roberts's task was written recall of randomly ordered pitches, whereas the present experiments featured performance of normal (nonrandom) musical sequences. Also, the amounts of delay and interpolated material may have been larger in the present task. Finally, serial position curves in recall of natural musical sequences may reflect more than working memory; long-term memories of familiar musical styles may also play a role. These differences suggest that natural musical materials and natural recall tasks such as performance are necessary to explicate domain-specific memory interference effects on serial position curves.

\section{Implications for Matching Approaches}

Matching proposals such as specificity of practice (Proteau, 1992) and TAP (Bransford, Franks, Morris, \& Stein, 1979; Morris et al., 1977) emphasize the facilitation of performance that occurs when conditions are similar during learning and test (an encoding-retrieval interaction). Our results, however, showed little effect of matching. Specificity of practice (SOP) posits that learning is specific to the conditions that prevail during skill acquisition, and that learning in the presence of responseproduced perceptual feedback leads to a dependence on that feedback at later test (see, e.g., Proteau, 1992; Proteau et al., 1992). Our manipulation of feedback presence/absence during learning and test is similar to the manipulation of visual feedback in experiments such as those of Adams et al. (1972), Elliot and Jaeger (1988), Proteau et al. (1987), and Proteau et al. (1992); however, in contrast to those studies, our findings showed no indication of dependence on feedback at test. There are a number of task characteristics that might be responsible for this difference in results. Most existing SOP research has used graded movements-for example, tasks such as aiming, which require a high degree of spatial accuracy. SOP may not be applicable to more discrete dependent variables such as our error measure, but a matching effect in music might be found if analyses were done on more continuous aspects of music performance, such as keystroke force on a piano or intonation on a violin. Second, SOP may apply only to factors that have an effect on performance during the learning phase; visual feedback has a strong effect during the learning of an aiming task, but auditory feedback did not affect performance during our music learning trials. Finally, feedback modality may be relevant; SOP may apply to visual but not auditory feedback. Any of these factors might be essential to SOP (see Schmidt \& Lee, 1999, pp. 318-321, for further discussion of specificity effects in motor learning).

The TAP framework proposes that test performance is a function of the similarity of conditions at learning and test (Bransford et al., 1979; Morris et al., 1977). TAP has been applied to verbal memory (e.g., Morris et al., 1977), motor learning (Fendrich, 1998; Lee, 1988), and memory for pictures (Srinivas, 1996). Recent TAP work has tried to specify the relevant aspects of similarity. Franks,
Bilbrey, Lien, and McNamara (2000) focused on the extent to which both task and stimulus matched at learning and test and stated that "the coded memory is a unique interactive combination of the intentional act and the stimulus situation" (p. 1141). Blaxton (1989), Graf and Ryan (1990), and Kolers and Roediger (1984) all took the view that performance at test will be facilitated to the extent that the cognitive operations (processes) during learning overlap with those during test. With either interpretation, a matching effect in music performance might be expected. Auditory feedback is plausibly an aspect of both music-as-stimulus and music-as-task, so matching the feedback conditions at learning and test should increase the similarity of both task and stimulus, leading to improved performance. Auditory feedback is also presumably relevant to the types of processing that take place. For example, Wright and Shea (1991) suggested that the extent to which processing is similar at learning and test depends on the contextual information available in the environment. Matching feedback at learning and test should thus cause greater overlap of processing (e.g., making the processing more conceptual or auditory), but this overlap did not lead to improved recall in our performance task. The absence of a significant matching effect in the music performance data poses a potential challenge for TAP.

\section{Conclusion}

Much recent work on memory has focused on the interaction between conditions during learning and recall, sometimes taking the strong position that encoding factors cannot be described without specifying retrieval conditions. Tulving (1979) argued that "no absolute answer can be given to the question of which of two encoding conditions was 'better'... any answer ... can only be given in relation to a particular retrieval condition" (p. 408). Similarly, Bransford et al. (1979) claimed that "the value or 'goodness' of particular acquisition activities can be defined only in relation to the nature of the test context" (p. 331). The finding that auditory feedback during learning improves memory, independent of retrieval conditions, provides counterevidence to such strong claims. Our findings do not invalidate the many demonstrations of matching effects, but they do suggest that matching may not be as universal or dominant a phenomenon as is sometimes assumed, and they support the view that some factors may facilitate learning regardless of conditions at test.

\section{REFERENCES}

Adams, J. A. (1971). A closed-loop theory of motor learning. Journal of Motor Behavior, 3, 111-149.

Adams, J. A., \& BraY, N. W. (1970). A closed-loop theory of pairedassociate verbal learning. Psychological Review, 77, 385-405.

Adams, J. A., Goetz, E., \& Marshall, P. (1972). Response feedback and motor learning. Journal of Experimental Psychology, 92, 391-397.

AdAms, J. A., GopHer, D., \& Lintern, G. (1977). Effects of visual and proprioceptive feedback on motor learning. Journal of Motor Behavior, 9, 11-22.

Baddeley, A. D., Cuscaro, W., Egstrom, G., Weltmen, C., \& 
WiLlis, M. (1975). Cognitive efficiency of divers working in cold water. Human Factors, 17, 446-454.

Baddeley, A. D., \& Hitch, G. J. (1994). Developments in the concept of working memory. Neuropsychology, 8, 485-493.

BANTON, L. (1995). The role of visual and auditory feedback during the sight-reading of music. Psychology of Music, 23, 3-16.

BARTLETT, F. C. (1932). Memory: A study in experimental and social psychology. Cambridge: Cambridge University Press.

Bilodeau, E. A., \& Bilodeau, I. M. (1961). Motor skills learning. In P. R. Farnsworth, O. McNemar, \& Q. McNemar (Eds.), Annual review of psychology (Vol. 12, pp. 243-280). Palo Alto, CA: Annual Reviews.

BilodeaU, I. M. (1966). Information feedback. In E. A. Bilodeau (Ed.), Acquisition of skill (pp. 255-296). New York: Academic Press.

BlaXton, T. A. (1989). Investigating dissociations among memory measures: Support for a transfer-appropriate processing framework. Journal of Experimental Psychology: Learning, Memory, \& Cognition, 15, 657-668.

Bransford, J. D., Franks, J. J., Morris, C. D., \& Stein, B. S. (1979). Some general constraints on learning and memory research. In L. S. Cermak \& F. I. M. Craik (Eds.), Levels of processing in human memory (pp. 331-354). Hillsdale, NJ: Erlbaum.

BRANSFORD, J. D., \& JoHnson, M. (1972). Contextual prerequisites for understanding: Some investigations of comprehension and recall. Journal of Verbal Learning \& Verbal Behavior, 11, 717-726.

BRooKs, L. R. (1968). Spatial and verbal components of the act of recall. Canadian Journal of Psychology, 22, 349-368.

Chaffin, R, \& Imreh, G. (1997). "Pulling teeth and torture": Musical memory and problem solving. Thinking \& Reasoning, 3, 315-336.

Craik, F. I. M., \& Lockhart, R. S. (1972). Levels of processing: A framework for memory research. Journal of Verbal Learning \& Verbal Behavior, 11, 671-684.

Craik, F. I. M., \& Tulving, E. (1975). Depth of processing and the retention of words in episodic memory. Journal of Experimental Psychology: Human Perception \& Performance, 104, 268-294.

Crowder, R. B. (1976). Principles of learning and memory. Hillsdale, NJ: Erlbaum.

Deutsch, D. (1980). The processing of structured and unstructured tonal sequences. Perception \& Psychophysics, 28, 381-389.

Drake, C., \& Palmer, C. (2002). Skill acquisition in music performance: Relations between planning and temporal control. Cognition, 74, 1-32.

Eich, E. (1989). Theoretical issues in state-dependent memory. In H. L. Roediger III \& F. I. M. Craik (Eds.), Varieties of memory and consciousness: Essays in honour of Endel Tulving (pp. 331-354). Hillsdale, NJ: Erlbaum.

Elliot, D., \& JAEger, M. (1988). Practice and the visual control of aiming movements. Journal of Human Movement Studies, 14, 279 291.

EYSENCK, M. W. (1979). Depth, elaboration, and distinctiveness. In L. S. Cermak \& F. I. M. Craik (Eds.), Levels of processing in human memory (pp. 89-118). Hillsdale, NJ: Erlbaum.

FENDRICH, D. W. (1998). Recognition benefits from the reinstatement of a spatial representation of motoric processing. Psychological Research, 61, 125-134.

FinNEy, S. A. (1997). Auditory feedback and musical keyboard performance. Music Perception, 15, 153-174.

FinNEY, S. A. (2001). FTAP: A Linux-based program for tapping and music experiments. Behavior Research Methods, Instruments, \& Computers, 33, 63-72.

Franks, J. J., Bilbrey, C. W., Lien, K. G., \& McNamara, T. P. (2000). Transfer-appropriate processing (TAP) and repetition priming. Memory \& Cognition, 28, 1140-1151.

Gates, A., \& BRADSHaW, J. (1974). Effects of auditory feedback on a musical performance task. Perception \& Psychophysics, 16, 105-109.

GiBSON, E. (1969). Principles of perceptual learning and development. New York: Appleton-Century-Crofts.

GRAF, P., \& RYAN, L. (1990). Transfer-appropriate processing for implicit and explicit memory. Journal of Experimental Psychology: Learning, Memory, \& Cognition, 16, 978-992.
Hall, C., \& LEAVITT, J. (1977). Encoding and retention characteristics of direction and distance. Journal of Human Movement Studies, 3, 88-98.

HAVLICEK, L. (1968). Effects of delayed auditory feedback on musical performance. Journal of Research in Music Education, 16, 308-318.

JACOBY, L. L., \& CRAIK, F. I. M. (1979). Effects of elaboration of processing at encoding and retrieval: Trace distinctiveness and recovery of initial context. In L. S. Cermak \& F. I. M. Craik (Eds.), Levels of processing in human memory (pp. 1-22). Hillsdale, NJ: Erlbaum.

JAMES, W. (1890). The principles of psychology (Vol. 1). New York: Holt.

Kolers, P. A., \& Roediger, H. L., III (1984). Procedures of mind. Journal of Verbal Learning \& Verbal Behavior, 23, 425-449.

LARGE, E. W. (1993). Dynamic programming for the analysis of serial behaviors. Behavior Research Methods, Instruments, \& Computers, 25, 238-241.

LASHLEY, K. (1951). The problem of serial order in behavior. In L. Jeffress (Ed.), Cerebral mechanisms of behavior (pp.112-136). New York: Wiley.

LEE, T. D. (1982). Encoding specificity: A reply to Crocker (1981). Journal of Motor Behavior, 14, 86-90.

LEE, T. D. (1988). Transfer-appropriate processing: A framework for conceptualizing practice effects in motor learning. In O. G. Meijer \& $\mathrm{K}$. Roth (Eds.), Complex movement behavior: The motor-action controversy (pp. 201-216). Amsterdam: Elsevier, North-Holland.

Lee, T. D., \& Hirota, T. T. (1980). Encoding specificity principle in motor short-term memory for movement extent. Journal of Motor Behavior, 12, 63-67.

MaInwaring, J. (1933). Kinaesthetic factors in the recall of musical experience. British Journal of Psychology, 23, 284-307.

Marteniuk, R. G. (1973). Retention characteristics of short-term memory cues. Journal of Motor Behavior, 5, 249-259.

Marteniuk, R. G., \& Rodney, M. (1979). Modality and retention effects in intra- and cross-modal judgements of kinaesthetic and visual information. British Journal of Psychology, 70, 405-412.

Morris, C. D., Bransford, J. D., \& FranKs, J. J. (1977). Levels of processing versus transfer appropriate processing. Journal of Verbal Learning \& Verbal Behavior, 16, 519-533.

Mowbray, G. H. \& Gebhard, J. W. (1958). Man's senses as information channels. In H. Sinaiko (Ed.), Selected papers on human factors in the design and use of control systems (pp. 115-149). New York: Dover.

MuRRAY, D. J. (1965). Vocalization-at-presentation, auditory presentation, and immediate recall. Nature, 207, 1011-1012.

Murray, D. J., Boudreau, N., Burggraf, K. K., Dobell, L., Guger, S. L., Leask, A., Stanford, L., Tate, T. L., \& Wheeler, J. (1999). A grouping interpretation of the modality effect in immediate probed recognition. Memory \& Cognition, 27, 234-245.

Palmer, C., \& Drake, C. (1997). Monitoring and planning capacities in the acquisition of music performance skills. Canadian Journal of Experimental Psychology, 51, 369-384.

Palmer, C., \& Meyer, R. K. (2000). Conceptual and motor learning in music performance. Psychological Science, 11, 63-68.

Palmer C., \& VAN de Sande, C. (1993). Units of knowledge in music performance. Journal of Experimental Psychology: Learning, Memory, \& Cognition, 19, 457-470.

Palmer C., \& VAN De SANDE, C. (1995). Range of planning in music performance. Journal of Experimental Psychology: Human Perception \& Performance, 21, 947-962.

Penney, C. G. (1989). Modality effects and the structure of short-term verbal memory. Memory \& Cognition, 17, 398-422.

Piston, W. (1987). Harmony (5th ed.). New York: Norton.

Proteau, L. (1992). On the specificity of learning and the role of visual information for movement control. In L. Proteau \& D. Elliot (Eds.), Vision and motor control (pp. 67-103). Amsterdam: Elsevier.

Proteau, L., \& Cournoyer, J. (1990). Vision of the stylus in a manual aiming task: The effects of practice. Quarterly Journal of Experiment Psychology, 42B, 811-828.

Proteau, L., Marteniuk, R. G., Girouard, Y., \& Dugas, C. (1987). On the type of information used to control and learn an aiming movement after moderate and extensive practice. Human Movement Science, 6, 181-189. 
Proteau, L., Marteniuk, R. G., \& Levesque, L. (1992). A sensorimotor basis for motor learning: Evidence indicating specificity of practice. Quarterly Journal of Experimental Psychology, 44A, 557575.

REPP, B. H. (1996). The art of inaccuracy: Why pianists' errors are difficult to hear. Music Perception, 14, 161-184.

REPr, B. H. (1999). Effects of auditory feedback deprivation on expressive piano performance. Music Perception, 16, 409-438.

Roberts, L. A. (1986). Modality and suffix effects in memory for melodic and harmonic musical materials. Cognitive Psychology, 18, 123-157.

Roberts, L. A., Millen, D. L. Palmer, C., \& Tartter, V. C. (1983). Modality and suffix effects in memory for music. Journal of the Acoustical Society of America, 74, 522A.

Roy, E. (1978). Role of preselection in memory for movement extent. Journal of Experimental Psychology: Human Learning \& Memory, 4, 397-405.

Rubin-RABSON, G. (1937). The influence of analytical prestudy in memorizing piano music (Vol. 220). New York: Archives of Psychology.

Rubin-Rabson, G. (1941). Studies in the psychology of memorizing piano music. VI: A comparison of two forms of mental rehearsal and keyboard overlearning. Journal of Educational Psychology, 32, 593602.

Salamé, P., \& BAdDeley, A. D. (1989). Effects of background music on phonological short-term memory. Quarterly Journal of Experimental Psychology, 41A, 107-122.

Salmoni, A. W., Schmidt, R. A., \& Walter, C. B. (1984). Knowledge of results and motor learning: A review and critical appraisal. Psychological Bulletin, 95, 355-386.

SchmidT, R. A. (1975). A schema theory of discrete motor skill learning. Psychological Review, 82, 225-260.

Schmidt, R. A., \& LeE, T. D. (1999). Motor control and learning: A behavioral emphasis (3rd ed.). Champaign, IL: Human Kinetics.
SLAmECKA, N. J., \& GRAF, P. (1978). The generation effect: Delineation of a phenomenon. Journal of Experimental Psychology: Human Learning \& Memory, 4, 592-604.

Smith, S., Glenberg, A., \& BJork, R. (1978). Environmental context and environmental memory. Memory \& Cognition, 6, 342-353.

SRINIVAS, K. (1996). Size and reflection effects in priming: A test of transfer-appropriate processing. Memory \& Cognition, 24, 441-452.

Tulving, E. (1979). Relation between encoding specificity and levels of processing. In L. S. Cermak \& F. I. M. Craik (Eds.), Levels of processing in human memory (pp. 405-428). Hillsdale, NJ: Erlbaum.

Tulving,\& Thomson, D. M. (1973). Encoding specificity and retrieval processes in episodic memory. Psychological Review, 80, 352-373.

Wright, D. L., \& Shea, C. H. (1991). Contextual dependencies in motor skills. Memory \& Cognition, 19, 361-370.

\section{NOTE}

1. Response-produced sensory feedback and knowledge of results (KR) are sometimes treated separately in the motor control literature; for example, KR has been defined as "verbal, terminal, augmented feedback about goal achievement" (Salmoni, Schmidt, \& Walter, 1984, p. 360). However, feedback and KR also have much in common; Salmoni et al. (1984) noted that feedback can be redundant with KR in some circumstances, and E. A. Bilodeau and Bilodeau (1961) also seem to have viewed feedback and KR as similar. Auditory feedback in music performance provides detailed information about errors in pitch (as well as information about duration, loudness, and other dimensions), and as such may function partially (or primarily) as KR; the differences are not crucial for the present article.

(Manuscript received November 2, 2001; revision accepted for publication September 9, 2002.) 